\title{
Diabetes Self-Management in the Age of Social Media: Large-Scale Analysis of Peer Interactions Using Semiautomated Methods
}

Sahiti Myneni ${ }^{1}$, PhD; Brittney Lewis ${ }^{2}$, MS; Tavleen Singh ${ }^{1}$, MS; Kristi Paiva ${ }^{2}$, MPH; Seon Min Kim ${ }^{2}$, BSc; Adrian V Cebula $^{2}$, MS; Gloria Villanueva ${ }^{2}$, BSc; Jing Wang ${ }^{2}, \mathrm{PhD}, \mathrm{MPH}, \mathrm{RN}$, FAAN

${ }^{1}$ University of Texas School of Biomedical Informatics at Houston, Houston, TX, United States

${ }^{2}$ Center on Smart and Connected Health Technologies, School of Nursing, The University of Texas Health Science Center at San Antonio, San Antonio, TX, United States

Corresponding Author:

Sahiti Myneni, PhD

University of Texas School of Biomedical Informatics at Houston

7000 Fannin Street

Suite 600

Houston, TX, 77030

United States

Phone: 17134860115

Email: sahiti.myneni@uth.tmc.edu

\section{Abstract}

Background: Online communities have been gaining popularity as support venues for chronic disease management. User engagement, information exposure, and social influence mechanisms can play a significant role in the utility of these platforms.

Objective: In this paper, we characterize peer interactions in an online community for chronic disease management. Our objective is to identify key communications and study their prevalence in online social interactions.

Methods: The American Diabetes Association Online community is an online social network for diabetes self-management. We analyzed 80,481 randomly selected deidentified peer-to-peer messages from 1212 members, posted between June 1, 2012, and May 30, 2019. Our mixed methods approach comprised qualitative coding and automated text analysis to identify, visualize, and analyze content-specific communication patterns underlying diabetes self-management.

Results: Qualitative analysis revealed that "social support" was the most prevalent theme (84.9\%), followed by "readiness to change" (18.8\%), "teachable moments" (14.7\%), "pharmacotherapy" (13.7\%), and "progress" (13.3\%). The support vector machine classifier resulted in reasonable accuracy with a recall of 0.76 and precision 0.78 and allowed us to extend our thematic codes to the entire data set.

Conclusions: Modeling health-related communication through high throughput methods can enable the identification of specific content related to sustainable chronic disease management, which facilitates targeted health promotion.

(JMIR Med Inform 2020;8(6):e18441) doi: $10.2196 / 18441$

\section{KEYWORDS}

diabetes; self-management; social media; digital health

\section{Introduction}

\section{Background}

Diabetes (specifically type 2 diabetes and prediabetes) is a leading public health burden and global health issue. As of 2019, more than 100 million US adults are now living with diabetes or prediabetes [1]. The total estimated cost of diagnosed diabetes in 2020 is \$327 billion, including \$237 billion in direct medical costs and $\$ 90$ billion in reduced productivity [1]. Individuals with diagnosed diabetes have annual medical expenditures that are $\$ 7900$ or approximately 2.3 times higher than they would be in the absence of diabetes $(\$ 13,700$ vs $\$ 5800)$ [2]. Diabetes can also lead to renal and cardiovascular complications [1]. Addressing lifestyle risk factors, such as poor diet and physical activity, is vital to diabetes prevention and management. Numerous interventions and public health campaigns have been 
developed to help patients incorporate new behaviors (eg, medication regimen) and modify existing risky behaviors (eg, poor diet) to prevent and manage diabetes (for reviews, see [3-7]). However, the growth rate of diabetes is steady, adding to the health care burden. Adherence to healthy behaviors (eg, proper nutrition) and management of prevailing health conditions (eg, medication adherence) requires a significant support infrastructure that targets individualistic factors and environmental influences for long time intervals $[8,9]$.

\section{Social Relationships and Health Management}

Recent research suggests that social relationships play an essential role in an individual's engagement in health issues [10-12]. For example, Christakis and Fowler's analysis of the Framingham data set shows an association between the behavior of members of an individual's social network and the likelihood of smoking cessation [13]. Positive effects of social relationships have been associated with chronic illness self-management [14-17]. Increased levels of social integration are also found to improve the overall wellbeing of individuals [18]. On the other hand, some studies indicate the negative influence of social relationships [19,20]. While community-based social interventions harnessing the positive effects of social contacts exist [21-24], the mechanisms underlying the impact of social relationships on multiple behavioral domains of Diabetes Self-Management (DSM) are not fully understood. Consequently, an understanding of the mechanisms in play for numerous behavioral domains within diabetes management is crucial to promote wellness regimens that can result in sustained adoption.

\section{Online Communities as Secondary Data Sources}

The ubiquity of online communities presents us with invaluable data sets in the form of electronic traces of peer interactions [25], which may help to understand social influence in diabetes management. Thanks to the ready availability and accessibility of the internet via mobile phones, peer interactions in online communities often occur in real time. They can provide rich documentation of certain crucial moments in everyday life that influence diabetes prevention and management [26]. Further, it is common for an individual to seek a related online community (eg, newly diagnosed with type 2 diabetes) and navigate the records of peers who have shared their experiences. With the support of online communities and an associated bank of collective knowledge, the individual reflects on the problem, explores available information, and feels able to act, thus eliciting multiple theoretical constructs described in existing models of behavior change ([27-31]. Emerging research shows the complex relationships between online social ties and individuals' self-management of health conditions, thus highlighting the utility of online peer interactions as secondary data sources [17,29]. While we must be cognizant of inferential generalizability [30], these platforms have a tremendous capacity to inform clinicians, behavioral scientists, and technology developers about human health behaviors and ways to harness knowledge from online social media to inform intervention design, content curation, and information dissemination [31-34]. A more in-depth analysis of such interactions provides us with a new lens to inform, enhance, and strengthen existing frameworks of diabetes care delivery, prevention, and management [29,31]. Previous studies on diabetes-related social media interactions have focused on general-purpose platforms such as Twitter and Facebook interventions, where data volume has ranged in the order of hundreds to billions [35-39]. A majority of these studies have attempted to understand the types of diabetes information disseminated, the levels of information spread, and user engagement facilitated by these platforms. However, our understanding of digital environments solely dedicated to diabetes prevention and self-management are quite limited. As such, the semantic context underlying general-purpose and health-specific platforms can vary greatly, consequently affecting the methodological underpinnings of large-scale studies for unpacking the DSM domain in social media.

In this paper, we describe our findings of large-scale analysis of peer interactions in the health-related online community focusing on diabetes management. In addition to abstracting thematic strands underlying peer interactions, we provide a more in-depth analysis of behavior change techniques that manifest in these online discussions using manual coding methods. Further, we extend the reach of qualitative analysis using high throughput computational methods to understand the thematic distribution of peer communication in a diabetes-specific online community. The insights gained from these investigations will enable us to gain a deeper understanding of the digital environment and the nature of the peer interactions they facilitate, inclusive of and beyond social support. Our findings will help us design an enhanced support infrastructure through the development of tailored education interventions and digital solutions that harness social support and influence to promote positive health changes. Such "healthier life" technologies offer considerable advantages over traditional approaches in affordability, scalability, user engagement, and personalization.

\section{Methods}

\section{Materials}

For this study, we focus on user interactions within the American Diabetes Association (ADA) online community, one of the largest online communities focusing on engaging patients with diabetes and their caregivers in optimizing self-health management [40]. Members are required to have a registered account with the ADA to share content and exchange messages within the online community. The data set spans eight years (2012-2019) and includes publicly available interactions. Behavior before and after diagnosis, treatment effectiveness, healthy behaviors (low carb diet, physical activity), medication adherence, blood glucose self-monitoring, and other topics are discretely captured in this data. For this project, we focused our analysis on type 2-related entries. A total of 80,481 randomly selected de-identified messages exchanged by 1212 members were included in this analysis. We chose type 2 diabetes as the focus of this study because health outcomes and disease management among these patients are impacted by their lifestyle behaviors (diet and physical activity), medication use, and self-monitoring of blood glucose. The research has been 
reviewed and exempted by the Institutional Review Board at the University of Texas Health Science Center at Houston.

\section{Theme Abstraction}

We adopted Directed Content Analysis [41] to identify the core concepts and unifying themes that relate to diabetes prevention and management. First, four independent coders characterized the communication between members of each community, assigning communication themes (inductively derived using grounded theory techniques [42] in our prior work [43]) to randomly selected messages that relate to diabetes prevention and management. Table 1 provides an overview of the qualitative analysis and coding categories. We coded 517 messages to assign thematic labels (shown in Table 1). Each message could have multiple codes applied dependent on the content of the message, and codes were individually and independently assigned by four coders. Each message will have a minimum of two independent coders applying codes. Coders then met and reconciled codes into a master coded document via weekly meeting discussion following iterative comparison and consensus building to ensure objectivity in the coding process. The qualitative analysis allowed us to explain how online platforms are utilized by individual users to mend the gaps in their social and information needs. Also, we conducted a more in-depth analysis of the messages to understand types of social support [44] and the taxonomy of behavior change techniques [45] observed in peer interactions. 
Table 1. Sample messages from the American Diabetes Association (ADA) mapped to the communication themes.

\begin{tabular}{lll}
\hline Theme & Definition & Sample message snippets from ADA \\
\hline Social support & $\begin{array}{l}\text { Messages where the content reflects the el- } \\
\text { ements of praise, advice, empathy, and } \\
\text { guidance }\end{array}$ & $\begin{array}{l}\text { Congratulations on a job well done - and Welcome to the 5\% club. Your } \\
\text { hard work and persistence paid off. Keep it up. :) }\end{array}$
\end{tabular}

Traditions

Messages that focus on community-specific rituals such as pledges or any engagement practices conducted by moderators or users

Teachable moments

Messages that describe incentives to make positive health changes

Obstacles

Messages focusing on hurdles to planned health practices

Pharmacotherapy

Relapse

Readiness to change

Cravings

Alternative medicine

Progress

Patient-reported Outcomes

Conflict

Miscellaneous

A message which contains questions or information not about an individual's health status or diabetes management
Messages with descriptions of relapse reasons or confessions

Messages that inspire to initiate positive health changes

Messages that capture real-time expressions of the urges to deviate from planned health behaviors

Messages that describe therapies that are not regarded as orthodox by the medical profession

Messages in which members communicate their progress based on objective health measures

A message that focuses on subjective progress (positive or negative)

A message which is argumentative or clarifying a point/topic (not necessarily supportive)

How did you do this morning? How've you been doing over time? Nobody knew back then that there would be 28,196 replies to ... question. Nobody expected that twice that topic would grow so large that we would have to start over again in a brand new topic to accommodate all those posts.

Stress can have a huge impact on your numbers. Even a single day can raise my numbers significantly and I have had longer periods of stress that I know upped my A1C. So when you are dealing with a stressful time you want to increase your exercise and decrease your carbs.

I did add 3 days of swimming that lasted for 3 months until my swim buddies got on different schedules. I do miss the sun and water so I'm on a search for other swimming holes and buddies. Transportation can be a hurdle, too.

Metformin may have a small effect reducing insulin resistance, but its main effect is to keep the liver from sending out too much insulin and over-compensating when blood glucose is a little low, like when it helps to prevent the dawn effect.

On the issue of my numbers being too high in general... that's a separate issue. I have gotten lax with exercise and eating too many carbs.

I discovered that I had to change "Can't" to "Don't" in my thinking. I "can't" eat that cookie... means "Poor me, someone... is not allowing me to eat that cookie"... I "don't" eat cookies... means that I have a choice it's not something that's part of my life. I am in control.

Do I miss stuffing my face with pizza or other carbilicious meals? I suppose so, but it's not much of a loss... I miss sugary snacks, I guess that the biggest change.

The article has a story of one woman who was getting ready to have a foot/leg amputated (after living with "a terrible wound for 5 years"), but she tried 'the sugar treatment' (my term) and ... She ended up not having an amputation.

This summer will mark 8 years since I have been diagnosed with Type 2 diabetes. So far low carb eating, exercise and metformin are keeping me at my target blood glucose numbers.

Do I sometimes want to go back? Yes and no. I feel much better now and I know I'm healthier now, so no, I don't want to go back.

Again I did not say it causes diabetes I said it can cause diabetes - which was the original question. I did not say that there is a direct link between alcoholism and diabetes - but the actions of an alcoholic can contribute to developing diabetes.

I'm almost done with my First semester of college. Can you believe that? I did lot hard work.

a machine-learning classifier to derive a measure of relatedness between a given message and the previously identified communication themes to estimate the distribution of different types of content across the ADA online community. Ten-fold cross-validation was applied to determine the best performing binary classifier for automating the classification of the entire set of messages. We have used Weka [48] and Semantic Vectors package [49] to build the pipeline for automated classification of ADA peer interactions. users, regardless of the specific terms used to express these concepts at the surface level. We applied latent semantic analysis [47], a method of distributional semantics in conjunction with 


\section{Results}

\section{Qualitative Analysis}

\section{Theme Abstraction}

Based on manual coding of 517 messages, "Social support" was the most common comment theme ( $n=439,84.9 \%$ of comments), followed by "readiness" ( $\mathrm{n}=97,18.8 \%)$, "teachable moments" $(\mathrm{n}=76,14.7 \%)$, "pharmacotherapy" $(\mathrm{n}=71,13.7 \%)$, and "progress" $(\mathrm{n}=69,13.3 \%)$, "obstacles" $(\mathrm{n}=48,9.2 \%$ of comments). Additional codes included, "miscellaneous" ( $\mathrm{n}=33$, $6.3 \%)$, "patient-reported outcomes" ( $\mathrm{n}=29,5.6 \%)$, "traditions" $(\mathrm{n}=25,4.8 \%)$, "conflict" ( $\mathrm{n}=24,4.6 \%)$, "alternative medicine" $(\mathrm{n}=7,1.3 \%)$, "relapse" $(\mathrm{n}=5,0.97 \%)$, and "cravings" $(\mathrm{n}=1$, $0.19 \%$ ). Given the very nature of the social forum, the majority of the messages exchanged in the ADA community were fostering empathy, affection, and reinforcement that are essential to the sustenance of healthy lifestyle changes. Medication use, motivators for change, and sharing progress also seem to play an important role in diabetes interactions in this community.

\section{Social Support-Anatomical Analysis}

A more in-depth analysis of messages specific to social support theme using House taxonomy [39] revealed that the most common form of social support provided was "informational" $(\mathrm{n}=361,82.2 \%)$, followed by "emotional" ( $\mathrm{n}=155,35.3 \%)$, and "appraisal" ( $n=9,0.02 \%)$. "Instrumental" support did not apply to our data set, given the lack of manifestation of tangible support (Table 2).

Further analysis revealed the specific behavior change techniques employed by ADA community users. "Social Support," "Shaping knowledge," "Feedback and Monitoring," and "Goals and Planning" were the most utilized behavior change techniques embedded within the messages related to social support theme.

Table 2. Social support analysis.

\begin{tabular}{lll}
\hline Types of social support & Definition & Example \\
\hline Informational & Providing advice, suggestions, and information & $\begin{array}{l}\text { "I wait for about } 6-7 \text { days of bg readings to } \\
\text { call a trend for myself when the differences } \\
\text { are small, but it is possible over a course of } \\
\text { days to note a slight uptick or downtick in bg." }\end{array}$ \\
Emotional & Expressions of empathy, love, trust, and caring & $\begin{array}{l}\text { "Way to go ....! Congratulations on changing } \\
\text { your way of eating and adding in all that exer- } \\
\text { cise." }\end{array}$ \\
Appraisal & Information that is useful for self-evaluation & "Did you ever have diabetes education classes, \\
& & or consult with a diabetes educator? Do you \\
know how to count carbs? Read here and learn \\
how to make your efforts achieve the best \\
possible outcomes."
\end{tabular}

${ }^{\mathrm{a}} \mathrm{N} / \mathrm{A}$ : not applicable.

\section{Beyond Social Support-Anatomical Analysis}

Figure 1 shows the thematic dispersion (excluding "Social Support") across various behavior change techniques, where the color scale represents the number of messages in which a given technique has been observed. "Feedback and monitoring" was the most diversely used technique, followed by "Shaping knowledge," "Goals and Planning," and "Repetition and substitution," and "Regulation." The least used behavior change techniques include "covert learning," "rewards and threat," and "natural consequences." 
Figure 1. Mapping of communication themes and behavior change techniques.

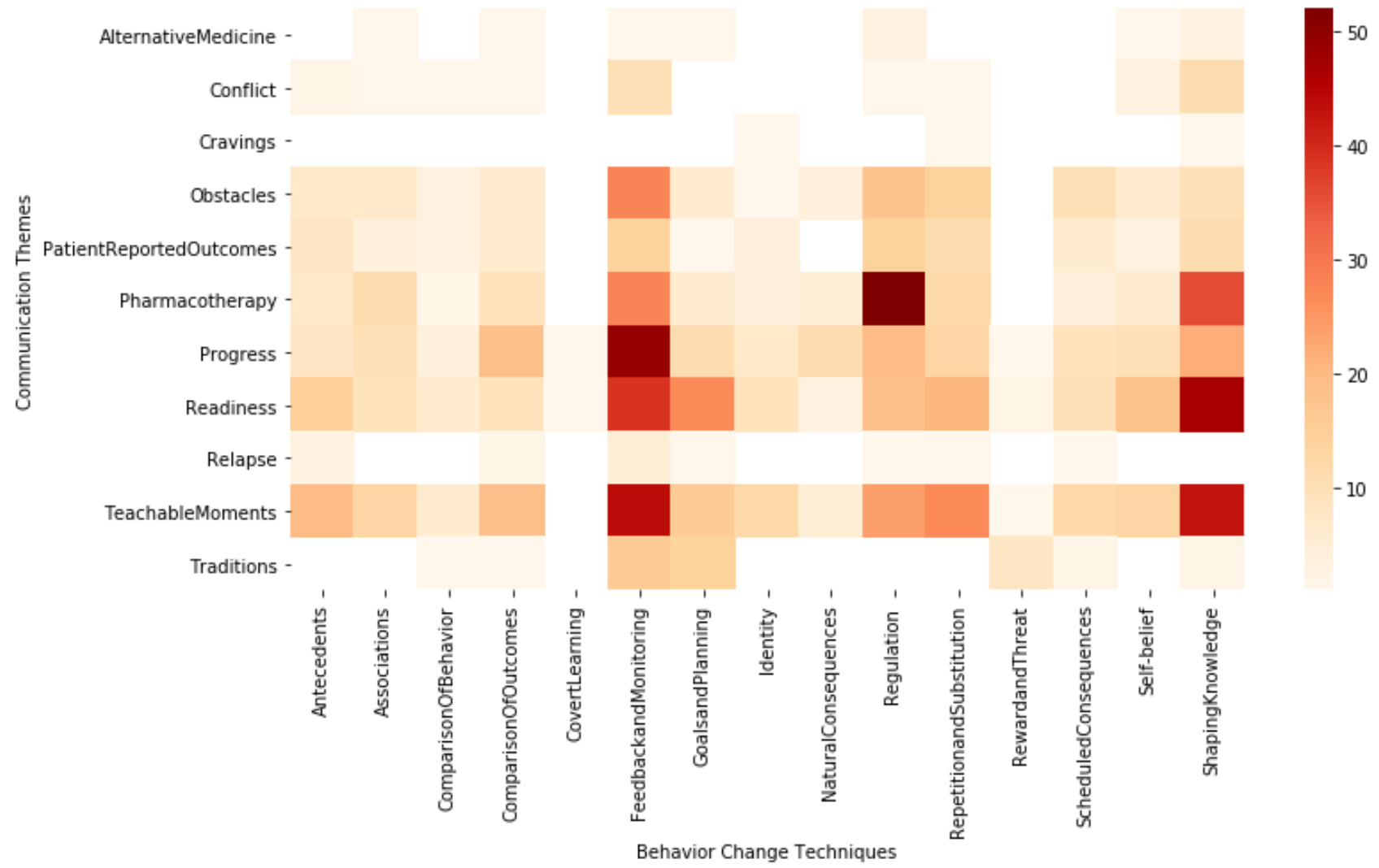

\section{Automated Classification}

The precision, recall, and f-measure for the cross-validation of the machine learning technique using the SVM classifier were $0.76,0.78$, and 0.77 , respectively. Table 3 provides a summary of the performance for the most commonly used classifiers.

Due to insufficient training examples in the training set, we disregarded 5 of the 13 themes for final classification. Due to a lack of semantic context, we have not included "miscellaneous" in our automated classification system. With the application of our automated classification to the rest of the ADA data set ( $\mathrm{n}=80,481$ posts), thematic coverage is as follows: social support $(74.2 \%)$, readiness to change (12.6\%), progress $(18.8 \%)$, obstacles $(10.2 \%)$, teachable moments $(16.4 \%)$, Pharmacotherapy (21.4\%), and Patient-reported outcomes (7.1\%).

Given the use of high throughput analytical methods to extend manual coding to the rest of the ADA data set, we were able to gain an understanding of the prevalence of DSM-related communication themes in this online community. Understanding thematic prevalence at large scale will now help us with the development of automated support systems using virtual coaching and chatbots for seamless and sustained user experience in online communities such as ADA.

Table 3. Machine learning classifiers applied to peer interactions.

\begin{tabular}{llll}
\hline Naïve & Recall & Precision & F-measure \\
\hline LibLinear & 0.64 & 0.66 & 0.65 \\
SVM $^{\mathrm{a}}$ & 0.76 & 0.78 & 0.77 \\
$\mathrm{KNN}^{\mathrm{b}}$ & 0.68 & 0.65 & 0.66 \\
$\mathrm{~J} 48$ & 0.72 & 0.66 & 0.69 \\
Naïve Bayes & 0.78 & 0.54 & 0.64 \\
\hline
\end{tabular}

${ }^{\mathrm{a}} \mathrm{SVM}$ : support vector machine.

${ }^{\mathrm{b}} \mathrm{KNN}$ : k-nearest neighbors.

\section{Discussion}

\section{Principal Findings}

In this digital era of connected health consumers, the interplay between theory-driven models of diabetes management and observed communication in social media is currently poorly understood [50]. Previous studies have shown that those with DSM who participate in social media forums or platforms saw a decrease in their $\mathrm{HbA}_{1 \mathrm{c}}$ (glycated hemoglobin) [51]. In the future, physicians may "prescribe" a form of social media or 
platform to reinforce healthy lifestyle choices outside of the clinic.

The results of this study facilitate the ecological analysis of DSM as embedded in peer interactions. This analysis may warrant refining existing models of DSM in the context of face-to-face (rather than online) communication. By using automated social media analysis methods, we will be able to scale up the qualitative analysis to extract relevant communication from large online social media data sets. Though analysis of diabetes management in online health communities is not without precedent [52], prior research does not address methodological scalability and shortcomings to model variances in multiple behaviors and underlying communication attributes in social settings. In this research, we conducted an inductive analysis of DSM strategies, without reliance on a single behavior change theory, as embedded in communication exchanges among members of a health-related online community. This effort enables the extraction of information context significant to behavior change events and social engagement levels in self-management of health-related activities.

Frequent use of online networks for social support, mainly informational, indicates a possible need for individualized diabetes support personnel outside of physician offices. It was noted that users would turn to the online forum to develop a consensus regarding the effectiveness of their medication regimen, exercise routines, and nutritional needs of people with diabetes. A minority of the comments provided solely emotional social support and many comments offered anecdotes to provide context for their diabetes journey. The online forum is a potential method of distributing information regarding their specific illness and sharing new recommendations, as users often share articles and studies they see as relevant or personal experience that helped them better manage their diabetes.

Current research on diabetes prevention and self-management has not addressed the effects of information and social environment. Prior work on content-inclusive network analysis [53-55] provided new methods for modeling network diffusion of communication attributes in online health communities, thus enabling us to disentangle the effects of the theoretical properties of exchanged health information and social structure on health outcomes. With the onset of mobile connectivity in the communication sector, messages exchanged in health-related online communities reflect the intricacies of human health as experienced in real time at the individual, community, and societal levels [33]. The majority of research studies on online health communities focusing on diabetes have analyzed peer-to-peer interactions based on social support categories facilitated by the platforms (eg, informational support, emotional support) [56-58]. However, social support is but one of the numerous interpersonal mechanisms facilitated by the social ties established in online communities. Existing theories of behavior change suggest a myriad of content-driven strategies to elicit specific socio-behavioral mechanisms beyond social support (eg, stimulus control, observational learning) to help individuals change their behavior and self-manage an illness $[43,59,60]$. Our qualitative analysis of underlying behavior change techniques in peer interactions has highlighted "feedback and monitoring" to be the most used technique, which emphasizes the complex functions of social relationships, which goes beyond the provision of social support. ADA-like platforms can help provide better self-health awareness for individuals through monitoring and knowledge acquisition.

\section{Limitations and Future Work}

Our qualitative coding has been limited to inductive analysis and mapping of behavior change techniques in a single online community. Future research should focus on mapping of these inductively derived themes to expansive theory-driven taxonomy such as the Behavior Change Taxonomy [45,60] using computational models for large-scale pattern recognition and identification of independent behavior strands within the DSM in online settings. Further, there may be differences in what is gained from using social media platforms like ADA based on user demographics. Future studies should consider age-specific barriers to information consumption and comprehension in social media platforms. Although we used multiple computational models to perform a large-scale analysis of ADA user interactions, the use of advanced deep learning methods from artificial intelligence research, such as Convolutional Neural Networks [61] and Bidirectional Encoder Representations from Transformers [62], may improve the training of the automated classification system.

Further analysis of peer communication can be deepened through sentiment analysis to find specific emotions in communication, such as anger, happiness, and others. Quantifying sentiments [63] can also help in differentiating their sentiments towards the interventions or other aspects of the behavior change process and regimen. This effort will, in turn, help interventionists identify attitudes and further motivation for user engagement that can arise from satisfaction/dissatisfaction with the intervention.

\section{Conclusions}

Behavior modification, such as balanced nutrition, an increase in physical activity, and medication adherence, is a critical component of DSM. Patient engagement in DSM consists of the adoption of healthy behaviors and abstinence from risky behaviors. However, the modification of such behaviors is challenging. Numerous public health efforts have been made to promote healthy behaviors over the years, but their utility and efficacy have been suboptimal. The utility of online social media to foster behavior change has been recognized as one sustainable solution. However, little is known about how we can harness social platforms to facilitate positive changes and promote DSM. Health-related online communities present a unique opportunity to improve our understanding of such socio-behavioral mechanisms, as communication in this context is digitally archived, permitting analysis of the dynamics of social influence as they manifest in peer interactions. Our methods have allowed us to abstract the essence of peer-to-peer communication in online communities at scale and to elucidate ways in which observable digital interactions relate to behavior modification endeavors as related to diabetes prevention and management. Our findings will provide the basis for an integrated approach to the problem of chronic disease management and underlying subtasks of behavior change. Such work will have implications for the design of behavior support 
technologies that offer automated personalization to improve

level.

self-management behaviors at the individual and population

\section{Acknowledgments}

The research reported in this publication was supported by the National Library of Medicine of the National Institutes of Health under Award Numbers 1R01LM012974-01A1, and University of Texas Health San Antonio Center on Smart and Connected Health Technologies pilot funding. The content is solely the responsibility of the authors and does not necessarily represent the official views of the National Institutes of Health.

\section{Conflicts of Interest}

None declared.

\section{References}

1. Centers for Disease Control and Prevention. National Diabetes Statistics Report, 2020. Estimates of Diabetes and Its Burden in the United States. Atlanta, GA. URL: https://www.cdc.gov/diabetes/pdfs/data/statistics/national-diabetes-statistics-report. $\underline{\text { Pdf }}$ [accessed 2020-05-30]

2. Herman WH. The economic costs of diabetes: is it time for a new treatment paradigm? Diabetes Care 2013 Apr 21;36(4):775-776 [FREE Full text] [doi: 10.2337/dc13-0270] [Medline: 23520368]

3. Norris SL, Engelgau MM, Narayan KM. Effectiveness of self-management training in type 2 diabetes: a systematic review of randomized controlled trials. Diabetes Care 2001 Mar 01;24(3):561-587. [doi: 10.2337/diacare.24.3.561] [Medline: 11289485]

4. Gillies CL, Abrams KR, Lambert PC, Cooper NJ, Sutton AJ, Hsu RT, et al. Pharmacological and lifestyle interventions to prevent or delay type 2 diabetes in people with impaired glucose tolerance: systematic review and meta-analysis. BMJ 2007 Feb 10;334(7588):299 [FREE Full text] [doi: 10.1136/bmj.39063.689375.55] [Medline: 17237299]

5. Renders CM, Valk GD, Griffin SJ, Wagner EH, Eijk Van JT, Assendelft WJ. Interventions to improve the management of diabetes in primary care, outpatient, and community settings: a systematic review. Diabetes Care 2001 Oct 01;24(10):1821-1833. [doi: 10.2337/diacare.24.10.1821] [Medline: 11574449]

6. Willey C, Redding C, Stafford J, Garfield F, Geletko S, Flanigan T, et al. Stages of change for adherence with medication regimens for chronic disease: Development and validation of a measure. Clinical Therapeutics 2000 Jul;22(7):858-871. [doi: 10.1016/s0149-2918(00)80058-2]

7. Strecher V, Wang C, Derry H, Wildenhaus K, Johnson C. Tailored interventions for multiple risk behaviors. Health education research Oct 1 2002;17(5):619-626. [doi: 10.1093/her/17.5.619]

8. Gallant MP. The influence of social support on chronic illness self-management: a review and directions for research. Health Educ Behav 2003 Apr;30(2):170-195. [doi: 10.1177/1090198102251030] [Medline: 12693522]

9. Berkman LF, Glass T, Brissette I, Seeman TE. From social integration to health: Durkheim in the new millennium. Social Science \& Medicine 2000 Sep;51(6):843-857. [doi: 10.1016/s0277-9536(00)00065-4]

10. Blanchard CG, Albrecht TL, Ruckdeschel JC, Grant CH, Hemmick RM. The Role of Social Support in Adaptation to Cancer and to Survival. Journal of Psychosocial Oncology 1995 Aug 15;13(1-2):75-95. [doi: 10.1300/j077v13n01 05]

11. Burg MM, Seeman TE. Families and Health: the Negative Side of Social Ties. Annals of Behavioral Medicine 1994;16(2):109-115.

12. Christakis NA, Fowler JH. The Collective Dynamics of Smoking in a Large Social Network. N Engl J Med 2008 May 22;358(21):2249-2258. [doi: 10.1056/nejmsa0706154]

13. Tillotson LM, Smith MS. Locus of control, social support, and adherence to the diabetes regimen. Diabetes Educ 1996 Jun 30;22(2):133-139. [doi: 10.1177/014572179602200206] [Medline: $\underline{8697963]}$

14. Nam S, Chesla C, Stotts NA, Kroon L, Janson SL. Barriers to diabetes management: patient and provider factors. Diabetes Res Clin Pract 2011 Jul;93(1):1-9. [doi: 10.1016/j.diabres.2011.02.002] [Medline: 21382643]

15. Lo R. Correlates of expected success at adherence to health regimen of people with IDDM. J Adv Nurs 1999 Aug 25;30(2):418-424. [doi: 10.1046/j.1365-2648.1999.01085.x] [Medline: 10457244]

16. Maclean HM. Patterns of diet related self-care in diabetes. Social Science \& Medicine 1991 Jan;32(6):689-696. [doi: 10.1016/0277-9536(91)90148-6]

17. Poirier J, Cobb NK. Social influence as a driver of engagement in a web-based health intervention. J Med Internet Res 2012 Feb 22;14(1):e36 [FREE Full text] [doi: 10.2196/jmir.1957] [Medline: 22356829]

18. Kaplan RM, Toshima MT. The Functional Effects of Social Relationships on Chronic Illnesses and Disability. In: Sarason BR, Sarason IG, Pierce GR, editors. Wiley series on personality processes. Social support: An interactional view. Hoboken, NJ: John Wiley \& Sons; 1990:427-453.

19. Wortman CB, Conway TL. The role of social support in adaptation and recovery from physical illness. In: Cohen S, Syme SL, editors. Social Support and Health. Orlando, FL: Academic Press; 1985:281-302. 
20. Alexander C, Piazza M, Mekos D, Valente T. Peers, schools, and adolescent cigarette smoking. Journal of Adolescent Health 2001 Jul;29(1):22-30. [doi: 10.1016/s1054-139x(01)00210-5]

21. van der Eijk M, Faber MJ, Aarts JW, Kremer JA, Munneke M, Bloem BR. Using online health communities to deliver patient-centered care to people with chronic conditions. J Med Internet Res 2013 Jun 25;15(6):e115 [FREE Full text] [doi: 10.2196/jmir.2476] [Medline: 23803284]

22. Myneni S, Fujimoto K, Cohen T. Leveraging Social Media for Health Promotion and Behavior Change: Methods of Analysis and Opportunities for Intervention. In: Cognitive Informatics in Health and Biomedicine. Cham: Springer; 2017:315-345.

23. Maloney-Krichmar D, Preece J. A multilevel analysis of sociability, usability, and community dynamics in an online health community. ACM Trans. Comput.-Hum. Interact 2005 Jun;12(2):201-232. [doi: 10.1145/1067860.1067864]

24. Ferguson T. Health online: How to find health information, support groups, and self-help communities in cyberspace. Reading, MA: Addison-Wesley; 1996.

25. Eysenbach G, Powell J, Englesakis M, Rizo C, Stern A. Health related virtual communities and electronic support groups: systematic review of the effects of online peer to peer interactions. BMJ 2004 May 15;328(7449):1166 [FREE Full text] [doi: 10.1136/bmj.328.7449.1166] [Medline: 15142921]

26. Heron K, Smyth J. Ecological momentary interventions: incorporating mobile technology into psychosocial and health behaviour treatments. British journal of health psychology 2010;15(1):1-39. [doi: 10.1348/135910709x466063]

27. Wicks P, Massagli M, Frost J, Brownstein C, Okun S, Vaughan T, et al. Sharing health data for better outcomes on PatientsLikeMe. J Med Internet Res 2010 Jun 14;12(2):e19 [FREE Full text] [doi: 10.2196/jmir.1549] [Medline: 20542858]

28. Lefebvre RC, Bornkessel AS. Digital Social Networks and Health. Circulation 2013 Apr 30;127(17):1829-1836. [doi: 10.1161/circulationaha.112.000897]

29. Centola D. Social Media and the Science of Health Behavior. Circulation 2013 May 28;127(21):2135-2144. [doi: 10.1161/circulationaha.112.101816]

30. Tufekci Z. Big Questions for Social Media Big Data: Representativeness, Validity and Other Methodological Pitfalls. ICWSM 2014:505-514.

31. Cobb NK, Graham AL. Health behavior interventions in the age of facebook. Am J Prev Med 2012 Nov;43(5):571-572. [doi: 10.1016/j.amepre.2012.08.001] [Medline: 23079184]

32. Graham A, Cobb C, Cobb N. The internet, social media, health decision-making. In: Handbook of Health Decision Science. New York, NY: Springer; 2016:335-355.

33. van Mierlo T, Li X, Hyatt D, Ching AT. Demographic and Indication-Specific Characteristics Have Limited Association With Social Network Engagement: Evidence From 24,954 Members of Four Health Care Support Groups. J Med Internet Res 2017 Feb 17;19(2):e40 [FREE Full text] [doi: 10.2196/jmir.6330] [Medline: 28213340]

34. Jane M, Hagger M, Foster J, Ho S, Pal S. Social media for health promotion and weight management: a critical debate. BMC Public Health 2018 Jul 28;18(1):932 [FREE Full text] [doi: 10.1186/s12889-018-5837-3] [Medline: $\underline{\text { 30055592] }}$

35. AlQarni ZA, Yunus F, Househ MS. Health information sharing on Facebook: An exploratory study on diabetes mellitus. J Infect Public Health 2016 Nov;9(6):708-712 [FREE Full text] [doi: 10.1016/j.jiph.2016.08.015] [Medline: 27618634]

36. Backa KE, Holmberg K, Ek S. Communicating diabetes and diets on Twitter - a semantic content analysis. IJNVO 2016;16(1):8. [doi: 10.1504/ijnvo.2016.075133]

37. Karami A, Dahl AA, Turner-McGrievy G, Kharrazi H, Shaw G. Characterizing diabetes, diet, exercise, and obesity comments on Twitter. International Journal of Information Management 2018 Feb;38(1):1-6. [doi: 10.1016/j.ijinfomgt.2017.08.002]

38. Rus HM, Cameron LD. Health Communication in Social Media: Message Features Predicting User Engagement on Diabetes-Related Facebook Pages. Ann Behav Med 2016 Oct 8;50(5):678-689. [doi: 10.1007/s12160-016-9793-9] [Medline: 27059761]

39. Liu Y, Mei Q, Hanauer DA, Zheng K, Lee JM. Use of Social Media in the Diabetes Community: An Exploratory Analysis of Diabetes-Related Tweets. JMIR Diabetes 2016 Nov 07;1(2):e4 [FREE Full text] [doi: 10.2196/diabetes.6256] [Medline: $\underline{\text { 30291053] }}$

40. American Diabetes Association. URL: https://community.diabetes.org/home [accessed 2020-05-30]

41. Hsieh H, Shannon SE. Three approaches to qualitative content analysis. Qual Health Res 2005 Nov;15(9):1277-1288. [doi: 10.1177/1049732305276687] [Medline: 16204405]

42. Mattley C, Strauss A, Corbin J. Grounded Theory in Practice. Contemporary Sociology 1999 Jul;28(4):489. [doi: $10.2307 / 2655359]$

43. Myneni S, Cobb N, Cohen T. In Pursuit of Theoretical Ground in Behavior Change Support Systems: Analysis of Peer-to-Peer Communication in a Health-Related Online Community. J Med Internet Res 2016 Feb 02;18(2):e28 [FREE Full text] [doi: 10.2196/jmir.4671] [Medline: 26839162]

44. House JS. Work, stress, and social support. In: Addison-Wesley series on occupational stress. Boston, MA: Addison-Wesley; 1981.

45. Michie S, Richardson M, Johnston M, Abraham C, Francis J, Hardeman W, et al. The behavior change technique taxonomy (v1) of 93 hierarchically clustered techniques: building an international consensus for the reporting of behavior change interventions. Ann Behav Med 2013 Aug 20;46(1):81-95. [doi: 10.1007/s12160-013-9486-6] [Medline: 23512568] 
46. Cohen T, Widdows D. Empirical distributional semantics: methods and biomedical applications. J Biomed Inform 2009 Apr;42(2):390-405 [FREE Full text] [doi: 10.1016/j.jbi.2009.02.002] [Medline: 19232399]

47. Landauer TK, Foltz PW, Laham D. An introduction to latent semantic analysis. Discourse Processes 1998 Jan;25(2-3):259-284. [doi: 10.1080/01638539809545028]

48. Hall M, Frank E, Holmes G, Pfahringer B, Reutemann P, Witten IH. The WEKA data mining software. SIGKDD Explor. Newsl 2009 Nov 16;11(1):10-18. [doi: 10.1145/1656274.1656278]

49. Widdows D, Ferraro K. Semantic Vectors: a Scalable Open Source Package and Online Technology Management Application. In: Proceedings of the Sixth International Conference on Language Resources and Evaluation (LREC'08). Paris: European Language Resources Association (ELRA); May 2008.

50. Riley WT, Rivera DE, Atienza AA, Nilsen W, Allison SM, Mermelstein R. Health behavior models in the age of mobile interventions: are our theories up to the task? Transl Behav Med 2011 Mar 24;1(1):53-71 [FREE Full text] [doi:

10.1007/s13142-011-0021-7] [Medline: 21796270]

51. Alcántara-Aragón V. Improving patient self-care using diabetes technologies. Ther Adv Endocrinol Metab 2019;10:2042018818824215 [FREE Full text] [doi: 10.1177/2042018818824215] [Medline: $\underline{30728941]}$

52. Greene JA, Choudhry NK, Kilabuk E, Shrank WH. Online social networking by patients with diabetes: a qualitative evaluation of communication with Facebook. J Gen Intern Med 2011 Mar 13;26(3):287-292 [FREE Full text] [doi: 10.1007/s 11606-010-1526-3] [Medline: 20945113]

53. Myneni S, Cobb N, Cohen T. Finding meaning in social media: content-based social network analysis of QuitNet to identify new opportunities for health promotion. Studies in health informatics and technology 2013:807-811.

54. Myneni S, Cobb NK, Cohen T. Content-specific network analysis of peer-to-peer communication in an online community for smoking cessation. AMIA Annu Symp Proc 2016;2016:934-943 [FREE Full text] [Medline: 28269890]

55. Myneni S, Fujimoto K, Cobb N, Cohen T. Content-Driven Analysis of an Online Community for Smoking Cessation: Integration of Qualitative Techniques, Automated Text Analysis, and Affiliation Networks. Am J Public Health 2015 Jun;105(6):1206-1212. [doi: 10.2105/ajph.2014.302464]

56. Johnson C, Feinglos M, Pereira K, Hassell N, Blascovich J, Nicollerat J, et al. Feasibility and preliminary effects of a virtual environment for adults with type 2 diabetes: pilot study. JMIR Res Protoc 2014 Apr 08;3(2):e23 [FREE Full text] [doi: 10.2196/resprot.3045] [Medline: 24713420]

57. Shaw RJ, Johnson CM. Health Information Seeking and Social Media Use on the Internet among People with Diabetes. Online J Public Health Inform 2011 Jun 22;3(1) [FREE Full text] [doi: 10.5210/ojphi.v3i1.3561] [Medline: 23569602]

58. Hilliard M, Sparling K, Hitchcock J, Oser T, Hood K. The emerging diabetes online community. Curr Diabetes Rev 2015 Jul 29;11(4):261-272 [FREE Full text] [doi: 10.2174/1573399811666150421123448] [Medline: 25901500]

59. Glanz K, Rimer B, Viswanath K. Health Behavior and Health Education: Theory, Research, and Practice. Hoboken, NJ: John Wiley \& Sons; 2008.

60. Abraham C, Michie S. A taxonomy of behavior change techniques used in interventions. Health Psychol 2008 May;27(3):379-387. [doi: 10.1037/0278-6133.27.3.379] [Medline: 18624603]

61. Kim Y. Convolutional neural networks for sentence classification. In: In Proceedings of EMNLP. 2014 Presented at: EMNLP; October 25-29; Doha, Qatar p. 25.

62. Devlin J, Chang M, Lee K, Toutanova K. Bert: Pre-training of deep bidirectional transformers for language understanding. In: In Proceedings of the 2019 Conference of the North American Chapter of the Association for Computational Linguistics: Human Language Technologies, Volume 2 (Short Papers). 2019 Presented at: Association for Computational Linguistics; June 2-7; Minneapolis, Minnesota p. 4171-4186.

63. Crossley SA, Kyle K, McNamara DS. Sentiment Analysis and Social Cognition Engine (SEANCE): An automatic tool for sentiment, social cognition, and social-order analysis. Behav Res 2016 May 18;49(3):803-821. [doi: $10.3758 / \mathrm{s} 13428-016-0743-\mathrm{z}]$

\section{Abbreviations}

ADA: American Diabetes Association

DSM: diabetes self-management

HbA $_{1 \mathbf{c}}$ : glycated hemoglobin

SVM: support vector machine

KNN: k-nearest neighbors 
Edited by G Eysenbach; submitted 26.02.20; peer-reviewed by K Radhakrishnan, H Stuckey, E Da Silva, K Pretorius; comments to author 18.03.20; revised version received 14.05.20; accepted 04.06.20; published 30.06.20

Please cite as:

Myneni S, Lewis B, Singh T, Paiva K, Kim SM, Cebula AV, Villanueva G, Wang J

Diabetes Self-Management in the Age of Social Media: Large-Scale Analysis of Peer Interactions Using Semiautomated Methods JMIR Med Inform 2020;8(6):e18441

URL: https://medinform.jmir.org/2020/6/e18441

doi: $\underline{10.2196 / 18441}$

PMID: $\underline{32602843}$

(CSahiti Myneni, Brittney Lewis, Tavleen Singh, Kristi Paiva, Seon Min Kim, Adrian V Cebula, Gloria Villanueva, Jing Wang. Originally published in JMIR Medical Informatics (http://medinform.jmir.org), 30.06.2020. This is an open-access article distributed under the terms of the Creative Commons Attribution License (https://creativecommons.org/licenses/by/4.0/), which permits unrestricted use, distribution, and reproduction in any medium, provided the original work, first published in JMIR Medical Informatics, is properly cited. The complete bibliographic information, a link to the original publication on http://medinform.jmir.org/, as well as this copyright and license information must be included. 